\title{
PM Only Probe Correction Method
}

National Cancer Institute

\section{Source}

National Cancer Institute. PM Only Probe Correction Method. NCI Thesaurus. Code C64232.

Make no adjustment to the perfect match (PM) probe levels. Defined in the documents available at http://bioconductor.org/packages/1.9/bioc/html/affy.html 